\title{
SPIRITUALITY, RELIGIOSITY AND NATIONALISM FROM THE PERSPECTIVE OF PUBLIC AND GLOBAL MENTAL HEALTH
}

\author{
Miro Jakovljevic $^{1}$, Asim Kurjak ${ }^{2}$, Ana Jerkovic ${ }^{3}$, Aziz Hasanovic ${ }^{4}$ \& Mijo Nikic ${ }^{5}$ \\ ${ }^{I}$ Department of Psychiatry and Psychological Medicine, University Hospital Centre Zagreb, Zagreb, Croatia \\ ${ }^{2}$ Department of Obstetrics and Gynecology, Clinical Hospital "Sveti Duh", \\ Medical School University of Zagreb, Zagreb, Croatia \\ ${ }^{3}$ Faculty of Economics \& Business, University of Zagreb, Zagreb, Croatia \\ ${ }^{4}$ Meshihat of Islamic Community in Croatia, Zagreb, Croatia \\ ${ }^{5}$ Faculty of Philosophy and Religious Studies, University of Zagreb, Zagreb, Croatia
}

received: 25.4.2019;

revised: 17.7.2019;

accepted: 25.9.2019

\section{SUMMARY}

Despite the intensive globalization and an attractive idea of human cosmopolitism the world is still divided into rival nations and religions, with confronting ethics and many war conflicts across the globe producing and perpetuating huge mental health problems. Radicalism, malignant nationalism, pathological religiosity and violent extremism and terrorism are important issues from the public and global mental health perspective. Public and global mental health research can inform preventive strategies and interventions against malignant nationalism, pathological religiosity and violent extremism. Healthy spirituality, sound religiosity and normal nationalism may contribute significantly to public and global mental health and promotion of empathic civilization. The aim of this paper is to address, stress and support mutual understanding and creative cooperation between religions and nations in promotion of public and global mental health, research, patient care and education.

Key words: public and global mental health - empathic civilization - nationalism - religiosity - collective mind - transnationalism

$$
* * * * *
$$

\section{INTRODUCTION}

We shall require a substantially a new manner of thinking if mankind is to survive Albert Einstein, 1879-1955

Our post-modern and post-truth the Antropocene epoch of globalization and the Transformation Science expansion, revolutions in information technology (infotech) and biotechnology (biotech), free market, fast exchange of global knowledge, communication without boundaries, and endless opportunities for travel and learning faces us with wonderful promises on one side as well as with many threats and dangers on the other side (Harrari 2017, 2018, Srica 2018). Globalization today is characterized by a rapid mobility of peoples, mass migrations, the proliferation of diaspora cultures, and a transnational sense of community provided by internet relationships (Juergensmeyer 2019). Despite the intensive globalization and an attractive idea of human cosmopolitism the world is still divided into rival nations and religions, with confronting ethics and many war conflicts across the globe producing and perpetuating huge mental health problems. Although we have been deeply engaged in a globalized era and an overall multicultural society in mainly secular states, there is a significant rise of violent nationalism and religious extremism throughout the European countries as well as throughout the world. Radicalism, malignant nationa- lism, pathological religiosity and violent extremism and terrorism are very important threats from the public and global mental health perspective (Bhui 2018). These topics related to the political issues and collective psychopathology, are too important to be left only to politics and politicians. The crucial question here is raised: how to create global systems of universal ethics, security, health and well-fare, in other words how to promote empathic civilization and global mental health? We all, all nations and religions are faced with same global challenges and doomsday scenarios: the nuclear war, the clash of cultures and civilizations, violent extremism and terrorism., ecological collapse and, technological disruption, collapse of liberalism based on ideas of human liberty and equality, and possible Big Data algorithm dictatorship making most people irrelevant. Not only that each of them is enough to destroy the future of our world, they also may reinforce one another, so that no single major nation or religion on its own may overcome any of these challenges and threatens. Making a new global identity of humanity and collective mind of humankind in which all nations and religions can exist together respecting each other and having enough good willing and wisdom to overcome the previously mentioned apocalyptic challenges and scenarios is an issue of huge importance for all humanistic disciplines, including psychiatry and other mental health disciplines.

\footnotetext{
Authors are members of the Croatian Forum of European Academy of Sciences and Art for promoting the study of scientific principles and practical application, but also sociological and anthropological aspects affecting mental health and human reproductive processes
} 
The challenging field of public and global mental health deals with mental health problems at the population, state and global level. The need for a public and global approach to protect and promote mental health as well as to reduce the burden of mental disorders is increasingly recognized (Wahlbeck 2015). Public and global mental health, religiosity and nationalism are inter-related phenomena associated with collective mind and that's why we need an overhaul of our basic understanding how nationalism and religiosity operate, in the light of mental health sciences. The aim of this paper is to address and stress the importance of healthy religiosity and sane nationalism for promotion and reinforcement of public and global mental health as well as a need for resolution of wicked problems of violent nationalism and morbid religiosity.

\section{RELIGIOSITY AND NATIONALISM AS PARTS OF COLLECTIVE MIND AND SOCIAL CONSCIOUSNESS}

\begin{abstract}
There are people who see the world as it is and ask why. We need people who see the world as it could be and ask why not.
\end{abstract}

Velimir Srića

There are many ways of understanding ourselves, our real human nature, our spirituality, religiosity and nationalism. In his best-seller book 'Sapiens - A Brief History of Humankind' Yuval Harrari (2011) explains a fascinating truth how mankind invented all boundaries that surround it today - from the nations and states, to the companies and brands. Humans as social beings, for evolutionary reasons strive to belong to a larger group, in order to have better chances for survival, to be protected and feel safer. On his path of individualization and psychosocial development, human beings are looking for a group to identify with and to ensure protection, security, an ideal to follow and trust, and reliable leadership that will look after his/her welfare as a parent, father or mother figure. That is why humans relate to concepts such as state, nation, religion, spiritual group, the church, etc. for which they are ready to sacrifice themselves, to do irrational things on behalf of them, and to pursue their authoritarian leader without questioning and critical thinking. According to the Abraham Maslow 's (1908-1970) theory human most important needs that motivate our behavior are those for physical survival, security, belonging, esteem and selfactualization. The belonging to a particular religion or nation, gives one the sense of protection, security and self-esteem as well as purpose and self-actualization. One may not always understand the deeper purpose, but if it belongs to the majority, it seems psychologically and rationally plausible. In one hand, to feel secure and protected is the duty of the state, and an individual must feel free to express one's values, political orientation, religious affiliation and many others. The need for belonging to a group has also a psychological significance for the individual - the collective consciousness of the group is stronger and according to numerous behavioral researches, the individual behaves differently, less conscious, less responsible, with less need for effort when in a group, than as an individual separated from the group.

We live in a world united by Infotech, global flows of people, ideas and goods which is a fertile ground for collective thinking, learning and strong collaboration at national, international and global level. According to Hocking et al. 2016) collective thinking (individualintrospective, biophysical-observations, social-narratives, ethical-principles, aesthetic-senses, sympatheticfeelings, reflective-synergistic understanding) is a multifaceted approach where each of seven ways of understanding is both a whole in itself, and a part of the whole of the individual's understanding. Examining wicked problems from the seven ways of understanding collective thinking is a method of getting a comprehensive understanding of problems as well as getting better ways of tackling them. Collective mind (see table 1) based on collective thinking and learning and action involves individual collective mind and community collective mind (Hocking et al. 2016). Collective action involves participation in groups, organizations and social movements that have shared goals and it is fundamental for identity formation through common experience and mutual interactions. The common experience leads to shared frame of reference and collective mental model. It is very important now to better understand relationship between the internal human mind (introspective and reflective understanding) and the external (biophysical, social or narrative, ethical, aesthetic and sympathetic understanding), as well as the relationship between the individual mind and the collective, the national mind and the cosmopolitan. It seems true what Stephen Hawking claimed that we are all now connected by the Internet, like neurons in a giant brain". Brain is place where biological, psychological, social and spiritual mechanisms meet each other and interact and create individual and collective identity, consciousness and mind. Our brains shape our ideas and cultures, but also the ideas we follow as well as our culture shape our brains.

Religiosity and nationalism are important components of the collective mind or collective consciousness that is unifying force within society and community. Holly books like Talmud, Bible and Quran, have been the source of powerful authority and crucial influence as well as religion movements influence the politics of many powerful countries and determine who are "us" and who are "them", who are friends and allies and who are opponents and enemies. Collective mind, consciousness or mental model represents a shared way of thinking among the members of the group or society. Concept of collective mind is very similar to the fundamental sociological concept of collective consciousness ("the totality of beliefs and sentiments common to the average members of society") developed by Emile Durkheim (1858-1917) to explain how unique individuals are bound together into collective units like social 
Table 1. Evolution of collective mind (Brown \& Harris 2014)

\begin{tabular}{|c|c|}
\hline State of the world & Transformational change \\
\hline A physical planet & $\begin{array}{l}\text { from a God given world to a fixed physical world: Rene Descartes (1569-1650)- } \\
\text { follow on Newton, Wilson, Dawkins - where to next: Popper, Ravetz }\end{array}$ \\
\hline $\begin{array}{l}\text { An evolving world } \\
\text { (The Darwinian mind) }\end{array}$ & $\begin{array}{l}\text { from a fixed physical world to a dynamic living world: Charles Darwin (1809-1892) - } \\
\text { follow on Gould, Watson, McClintock - where to next: Teilhard de Chardin }\end{array}$ \\
\hline $\begin{array}{l}\text { A self-organizing world } \\
\text { (The Gaian mind) }\end{array}$ & $\begin{array}{l}\text { from a dynamic living world to a self-organizing world: James Lovelock (1919-) - } \\
\text { follow on Margulis, Odum, Roszak - whereto next: Gregory Bateson }\end{array}$ \\
\hline $\begin{array}{l}\text { A networked world } \\
\text { (The cybernetic mind) }\end{array}$ & $\begin{array}{l}\text { from a self-organizing world to a world shaped by human mind: Norbert Wiener } \\
\text { (1894-1964) - follow on McLuhan, Page and Brin, Zuckerberg - where to next: } \\
\text { Christopher Alexander }\end{array}$ \\
\hline $\begin{array}{l}\text { A synergistic world } \\
\text { (The collective mind) }\end{array}$ & $\begin{array}{l}\text { from the idea of dominating human mind to a synergy among the non-living and living } \\
\text { systems, and human mind: follow on: The collective mind - A collective society }\end{array}$ \\
\hline
\end{tabular}

groups and societies. Collective consciousness "refers to the set of shared beliefs, ideas, attitudes, and knowledge that are common to a social group or society" and "which informs our sense of belonging and identity, and our behavior" (Cole 2019). Collective consciousness is related to the activity of mirror neurons and thus it can be defined also as "a shared sense of being together with others in a single or unified experience" (Combs \& Krippner 2008). Social institutions are those which produce collective consciousness, for example, the church fosters religiosity among groups of people affiliated with different religions, the state and politics foster patriotism and nationalism, using the news and popular media, police and judiciary to mold people in compliant citizens and workers. "Collective consciousness is the result of social forces that are external to the individual, that course through society and work together to create social phenomenon of the shared set of beliefs, values, and ideas that compose it" (Cole 2019). Human beings as members of groups and community internalize the shared set of norms, beliefs, values, and ideas and make the collective consciousness a reality by doing so, reaffirming and reproducing them by rituals, customs and living in ways that reflect them (Cole 2019). According to E. Durkheim when social groups are quite homogenous, the collective consciousness results in a "mechanical solidarity as automatic binding together of people into a collective through their shared values, beliefs and practices (see Cole 2019).

In addition to consciousness, collective mind, as a phenomenon common to the whole of society and culture, involves also collective unconsciousness and archetypes. The collective mind represents the unified consciousness and unconsciousness, and the unified self of the group or community like nation, religion or society. According to Carl Jung (1875-1961) all the most powerful ideas and concepts in religion, philosophy, science and politics can be followed back to archetypes that symbolize basic human motivations, values and personalities as basic foundation of how to be human. Collective unconsciousness represents a part of psyche which retains and transmits the common psychological heritage of mankind. The both unconscious and conscious collective mind are composed of the two sides: the light (love, compassion, empathy, altruism, solidarity) and dark side (repressed ideas, weaknesses, prejudice, envy, hate, aggression, greed). Our collective mind sets are a reflection of the politics, philosophy, science and religion throughout the whole history. According to Brown \& Harris (2014) "place and ethnic group can be transcended by identifying our human place as the entire globe and the current chaotic instability may be seen as the birth pangs of a new world, a world of collective human thinking and endeavor". However, "there is a kind of dance here between systems and stories, the individuals in families in communities in global networks", and "even as we nurture our collective mind through global communication, our future unfolds in connecting and re-connecting people to place, and nurturing their sense of self through authentic experience of belonging to and caring for something material and permanent" (Waltner-Toes 2014). We completely agree with Waltner-Toes (2014) that we need diverse communities of interest, emerging from different cultural histories which exist together and enrich each other in multiple and emerging forms of partnership, recognizing their fundamental dependence on each other. Here it is useful to remind on the spirit of African Ubuntu: I am I because of you; you are you because of me.

\section{HEALTHY OR NORMAL VS. MORBID OR PATHOLOGICAL NATIONALISM AND RELIGIOSITY}

Thinking well is wise; planning well, wiser; doing well wisest of all.

Persian proverb

Europe as well as the whole world is being caught in the crossfire between nationalist and internationalists, globalists or cosmopolitans with significant presence of violent nationalism and religious extremism. The terms nationalism and religiosity itself are a subject to different defining and interpretations (see table 2 for clear understanding), commonly demonized because opinion makers, intellectual and political leaders have tended to give some wrong and distorted meanings and connotations to these phenomena. 


\section{Table 2. Some important definitions}

Religion: 1. an organized system of values and beliefs that serve as moral and social guides. Many cultures have developed their own religious systems. Most religions may have developed concepts dealing with the origins of life, moral right and wrong behavior, and assumptions about afterlife (Corsini 2020). 2. a system of human norms that is founded on a belief in a superhuman order (Harrari 2011).

Religious instinct hypothesis: a postulate that all humans have a tendency to want to believe in a religion, to practice certain rituals, and to act according to the principles of religion (Corsini 2020).

Religious identity: the sense of group membership to a religion and the importance of this group membership as it pertains to one's self concept (Wikipedia https://en.m.wikipedia.org>wiki).

Religious nationalism: the relationship of nationalism to a particular religious belief, dogma or affiliation, predicated on the politicization of religion and/or the influence on politics (Wikipedia).

Nation: 1. people in land under single government - a community of people or peoples living in a defined territory and organized under a single government; 2 . people of same ethnicity - a community of people who share a common ethnic origin, culture, historical tradition, and, frequently language, whether or not they live together in one territory or have their own government (Encharta Concise English Dictionary 2001).

Nationality: 1.citizenship of particular nation - the status belonging to a specific nation by origin, birth, or naturalization; 2. people forming nation-state - a people with a common origin, tradition, and often language, who form or are capable of forming a nation-state; 3. ethnic group within a larger entity - an ethnic group that is part of a larger entity such as a state (Encharta Concise Dictionary 2001).

Nationhood: political independence as a separate nation (Encharta Concise English Dictionary 2001).

National consciousness: a shared sense of national identity that is a shared understanding that a people group shares a common ethnic/linguistic/cultural background; a first step towards the creation of nation (Wikipedia https://en.m.wikipedia.org>wiki).

National character: common personality characteristics that differentiate national and ethnic groups. Once a topic of considerable research, often flawed because it measured value-laden traits (perseverence, punctuality), ignored variation, within the group, and emphasized description rather than explanation (Corsini 2002).

Nationalism: 1. desire for political independence - the desire to achieve political independence, especially by a country under foreign control or by a people with a separate identity and culture but no state of their own; 2 . patriotism - proud loyalty and devotion to a nation; 3.excessive devotion to nation - excessive or phanatical devotion to a nation and its interests, often associated with a belief that one country is superior to all others (Encharta Concise English Dictionary 2001; 3. "advocacy of or support for the interest of one's own nation, especially to the exclusion or detriment of the interests of other nations" (the Oxford English Dictionary).

Ultranationalism: an extreme nationalism that promotes the interest of one state or people above all others (Wikipedia).

Long-distance nationalism: a nationalism which is structurally embedded in a transnational network: people who comfortably reside in a new country but their attachment to ancestral homeland may be far more intense than their technical loyalty to the new country of residence to which s/he might be bind with the act of citizenships (see Skrbis 2001).

Chauvinism: excessive patriotism, typically with attending a low opinion of other countries and cultures. Derives from Nicolas Chauvin, a military man with an unshakable devotion to Napoleon Bonaparte (Corsini 2002).

Patriotism or national pride: the feeling of love, devotion and sense of attachment to a homeland and alliance with other citizens who share the same sentiment. It can be combination of different feelings relating to one's own homeland, including ethnic, cultural, political or historical aspects (Wikipedia https://en.m.wikipedia.org $>$ wiki).

Sociocentrism: a tendency to identify with one's own social group to the extent that its group norms and prescriptions form a standard against which other people are judged. Usually refers to smaller social groups whereas ethnocentrism refers to a larger ethnic, religious, racial, or national groups (Corsini 2002).

Religiocentrism: the conviction that a person's own religion is more important than or superior to other religions (Corsini 2002).

Faithism: 1.discrmination towards a person or group of people solely dependent on their faith, beliefs or religion - used in place of racism when applicable; 2 . belief that faith or religion is the primary determinant of human traits and capacities and that religious differences produce an inherent superiority of a particular religion of beliefs (https://definithing.com>faithism); 3 .

Fideism: exclusive or basic reliance upon faith alone, accompanied by a consequent disparagement of reason and utilized especially in the pursuit of philosophical or religious truth (Amesbury R: Fideism.Stanford Encyclopedia of Philosophy. https://plato.stanford.edu >entries).

Ethnocentricity: an attitude of members of tribe, clan, or nation that they are superior by reason of natural selection or divine predeliction to others (Corsini 2020).

Ethnic surge: in social psychology, the recent growth of ethnic issues, particularly the assertiveness of minorities who use cultural or racial symbols as resources in the competition over resources (Corsini 2002).

Cosmopolitanism: the ideology that all human beings belong to a single community, based on shared morality, mutual respect despite their differing religious, political, etc. beliefs. a shared economic relationship, or a political structure that encompasses different nations (Wikipedia https://en.m.wikipedia.org $>$ wiki).

Globalism: the belief or advocacy that political policies should take worldwide issues into account before focusing on national or state concerns (Encharta Concise English Dictionary 2001).

Internationalism: 1.cooperation between countries - a policy or spirit of cooperation and mutual understanding between countries; 2 . interest in other countries - a willingness and ability to understand and respect the concerns, attitudes, and ways of life of other countries (Encharta Concise English Dictionary 2001.

Transnationalism: represents a phenomenon of 'cross-border' living where, thanks to modern technology and infra-structure, individuals and communities maintain social existence both in their current country of residence and their country of origin (see European Commission 2012). In the religious context it refers to the fluidity religion across borders.

Populism: politics or political ideology based on the perceived interest of ordinary people, as opposed to those of a privileged elite (Encharta Concise English Dictionary 2001

Eurpeanism: 1. a term that encapsulates the norms and values that Europeans have in common, and which transcend national or state identity (Wikipedia); 2. an attachment or allegiance to the traditions, interests, or ideals of Europeans (Merriam-Webster Dictionary). 
Table 3. Common characteristics of religiosity and nationalism

Positive characteristics: the sense of belonging, the sense of protection and security, the sense of pride, internal social bonding, the sense of serving to something sacred or a sacred cause.

Neutral characteristics: part of one's identity, focus on the group and not on the individual, urge to spreading and gaining number, crowd behavior, hierarchy not democracy - usually top down decision-making.

Potential negative characteristics: exclusiveness and 'the chosen ones' belief, unconditional trust, inferiority of the individual in comparison with the collective, hostility against different groups and individuals who oppose the group.

Mental health, spirituality, religiosity and nationalism are fascinating and controversial, but mutually interconnected issues characterized with a lot of misunderstanding and misinterpreting as well as many debatable and arguable aspects. All of them have been connected with ideology and politics in various ways since distant times. The both religiosity and nationalism are powerful motivating and identity-formation forces that may radically change mental functioning, behavior, social, spiritual and political experience. It is interesting that they have some common characteristics, both positive and negative (see table 3 ). Mostly the same psychological phenomenon lies beneath both, leading to the mixture of religion and politics, and only through individualization and awareness can both be transcended and consequently well-integrated in one's existence and identity. This is why there is a saying that cosmopolitanism means a better understanding of our roots and a better integration in our domicile nation - the higher and broader a human expands its consciousness, the better it can serve humanity on a daily practical and local basis: think globally, act locally.

In order to escape misunderstanding, here it is useful to make difference between religiosity and spirituality. Spirituality is usually recognized as the search for meaning and purpose in life, for a personal connection with transcendent realities and truths, and for interconnectedness with humanity, while religiosity is defined as codified, institutional and outward expression of spirituality and faith. According Ferrer (2002) spirituality is a basic transformative process that involves a shedding of narcissism, self-centeredness, self-separation, selfpreoccupation, and so on. Spiritual narcissism represents a spiritual distorsion and misuse of spiritual practice, energy, or experience, manifesting as ego-inflation with grandiosity fueled by spiritual energies, selfabsorption with a preoccupation by own spiritual status and achievements, and spiritual materialism with the appropriation of spirituality to strengthen egoic way of life (Ferrer 2002). Nationalism and religiosity may be both blessing and curse, healthy-minded and sickminded, as well as religious and nationalistic ideas may be sound or insane, salutogenic or pathogenic (Griffith 2010). According Pargament (1997) religious coping can be positive and negative and may serve 5 purposes: 1. spiritual (meaning, purpose, hope); 2. self-development (positive identity); 3. resolve (self-efficacy, comfort); 4. sharing (closeness, connectedness to community); and 5. restraint (helps keep emotions and behavior under control). Healthy-minded and sick (distorted or pathogenic) expressions of faith and nationalism are quite distinct - in the intentions, in the expectations, and in the observed effects and outcomes in the practice. Sound religiosity and healthy minded nationalism are associated with self-esteem and respect for others, empathy, compassion, creativity, open-mindedness, selfesteem, altruism and social responsibility. Healthy minded faith and nationalism may be the fuel that produces constructive social and cultural transformation - it inspires and directs acts of compassion, mercy, and justice (Levin 2009). The relationship between individual and collective mental health problems on one side and religiosity and nationalism on the other side is twoway: experiencing mental health problems increases risk of practicing morbid religiosity and violent nationalism and vice versa morbid religiosity and malignant nationalism induces many mental health problems. The misunderstanding, misinterpreting and misquoting of study results on the presence of psychiatric diagnosis or mental disorders among individuals involved in radicalism and violent extremism has strengthen stigmatization on people living with mental illness as well as negative repercussions for primary, secondary or tertiary prevention (De Marinis \& Boyd-MacMillan 2019).

Regarding nationalism and patriotism there is also a disagreement, whether and when they are a good or bad, normal or morbid phenomenon. Patriotism is commonly conceptualized as positive and nationalism as negative phenomenon. Nationalism means some kind of attachment to the nation, but the word nation is itself ambiguous because it may have an ethnic and a political character. That's why some people prefer the word patriotism which does not have any ethnic overtones. In other words, nationalism and patriotism and very similar and inter-related phenomena: nationalism means attachment and devotion to nation and patriotism to homeland or country. Despite the danger from its morbid forms, normal or healthy nationalism provides the cohesion that is necessary for a people to be able to rule the society. Nationalism may be benign and malign, sound or normal and morbid. Morbid nationalism can be manifested as xenophobia, chauvinism, and malignant genocidal nationalism, oikophobia and metaphrenia. Oikophobia (greek oikos - home, house, homeland; phobia fear) is the opposite extreme of xenophobia (xenos stranger, phobia - fear): as xenophobia refers to the fear or hatred of strangers and foreigners), so oikophobia refers to the fear or hatred of home or one's own society, nation or civilization. Metaphrenia (meta - over, beyond; phrenos - soul) refers to the mental state of turning away from family, here from national interests toward 
personal goals such as business (Corsini 2002). Chauvinism is a form of extreme patriotism and nationalism with an irrational belief in own national superiority or dominance (Wikipedia 2019). British term jingoism retains the meaning of chauvinism strictly in its original sense as an attitude of belligerent nationalism.

At the end of the day, one can say that regarding the both religiosity and nationalism it is very important to make distinction between path and pathology, between virtues and well-being promoting religion and nation on one side and hate promoting pathological religiosity and morbid nationalism on the other. Both religion and nationalism in their many forms can bring people 1 . a mission-discovery process, sense of meaning, personal integrity and purpose, 2. inspirations, values and the fuel to be good, do good and serve others, 3. a deep enjoyment of life, clinical and personal recovery from illness. Finding love, power, freedom, meaning, purpose and happiness in life is a fundamental challenge for everybody in all cultures. Healthy spirituality has been linked with higher self-esteem and optimism, more love, hope, positive thinking and positive mood states as well as improved treatment outcome in medicine. The need to have uplifting experiences and to be part of something larger than oneself is essential to the personal narratives of many people. Certain expressions of distorted religious faith may serve as a source of or may reflect psychological conflict (Levin 2009) and/or psychopathology. Distorted and pathogenic faith can indeed be an impediment to well-being and healing, no serious observer would deny this point (Levin 2009). Healthy-minded spirituality, religiosity and nationalism are the wealth of nations. Public and global mental health is essential to the attainment of peace and security and healthy minded nationalism and religiosity may give a significant contribution in their promotion.

\section{VIOLENT EXTREMISM, NATIONALISM AND RELIGIOSITY FROM PSYCHOCULTURAL PERSPECTIVE}

Madness is something rare in individuals - but in groups, parties, nations, and ages it is the rule. Friedrich Nietzsche (1844-1900)

Violent radicalization may be conceptualized as a morbid or malignant, individual and collective psychopathological process related to insane or distorted mental models of nationalism and religiosity, often facilitated by recruitment and training, by which an individual or group becomes increasingly committed to politically motivated violence, particularly against civilians (Bhui et al. 2012). Mental models are about mental functioning, information processing and experiencing and defining the self and others. According to Senge (2006) mental models are deeply ingrained assumptions, beliefs, generalizations, or pictures and visions that influence how we understand the world and how we operate in the world and create our narratives and life stories. From the psychological standpoint, mental models can be divided into individual and collective ones. A mental model that includes our way of perceiving ourselves, others and the world around us, has a substantial impact on our behavior throughout both personal and political life. Two people with different mental models can observe the same event and describe it differently (Senge 2006). A mental model includes beliefs about the functioning of the world (the facts of life), as well as values that mirror ideological, moral and ethical principles. Unlike the facts of life that are evidence-based, values come as a result of an individual, group or collective judgements and visions. When people with similar mental models truly share a political vision they are connected in the political psycho-culture and bound together by common aspirations and goals. Our national, religious, cultural, political, and social identities can be narrower or wider, and be expressed through an "us and them" conceptual orientation, where "the others" may be defined or perceived with various degrees of likeness, trust and respect, either as friends, rivals, or enemies.

\section{The sense of superiority and narcissistic nationalism and religious extremism}

Narcissism (a pervasive pattern of grandiosity, selfoverestimation, need for admiration, and lack of empathy) is a severe moral disorder that affects not only narcissistic individuals, but also, in an ever increasing manner, the larger groups like nations. The American historian Christopher Lash (1980) recognized in 1970s what he described as a 'culture of narcissism'. Narcissistic societies commonly operate in similar ways as narcissistic individuals (Gerhardt 2010). Narcissistic nationalism includes the cognition of superiority (basically, the belief that "we are OK since we are better/ more important than the others"), self-satisfaction, lack of empathy and an exalted affectedness ("others exist in this world only to admire us and approve of us"), egoistic motivation ("others exist in this world only to satisfy our needs"), as well as double moral standards and egocentric and autocratic behavior aiming at abuse and subordination of others.

\section{National demoralization and depressive nationalism}

Depression represents an individual or a collective moral breakdown characterized with the lack of satisfaction, meaning, hope, self-esteem and self-confidence and power. It can be a sign of personal or collective crisis, an individual psycho-pathological occurrence and a sign of depressive disorder, but also a collective psycho-political phenomenon tagged as a depressing political psycho-culture. Depressive political culture includes negative cognition (in essence, the belief that "we are far from being OK, we are actually weak and incompetent, while others are far better, far more competent and far stronger than us", that is to say, pessimistic and fatalistic mindset and the lack of selfesteem), negative affectedness (frequent bad moods, 
disappointment, the feeling of helplessness and hopelessness, dejection), negative motivation (lack of interests, lack of inspiration, lack of energy, lack of ideals, withdrawal) and inappropriate behavior (playing the role of victim, passivity, passive-aggressive behavior, auto-destructive behavior). The sense of national or religious inferiority may motivate violent collective activity, e.g. xenophobia, as therapy. What actually stands in the very heart of passive-aggressive behavior is a suppressed rage that, if accumulated, might lead to mutiny and an aggressive explosion of violence.

\section{Omnipotence, spectacle and exaltation: manic nationalism and manic religiosity}

Manic psycho-culture or mental model includes unrealistic, pompously-positive cognition (the core belief thereby being the following: "we are more than just OK, we are supreme, far better, more honest, more deserving, more capable and stronger than others"; it goes hand in hand with hyperoptimistic and megalomaniac self-perception, underestimation of danger, vaulting associations, self-overrating). It also includes a high-pitched affectedness (hyperthymia, unrealistic optimism), motivation ("I am powerful, I can do anything", going hand in hand with irritability, hyperergia), inappropriate vaulting behavior (playing the role of savior or persecutor, hyperactivity, proneness to aggressive or irrational behavior, risky behavior).

\section{The feeling of jeopardy and paranoid nationalism}

Paranoid disorder is of the outmost importance both as an individual psychopathological phenomenon and a sign of mental disorder, and as a collective psychopolitical phenomenon known as the paranoid political culture. Paranoia and aggressiveness almost always come hand in hand, both when it comes to individual and to collective pathology. A paranoid political culture is unexceptionally associated with conflicts, war and prosecution of those who disagree. From psychocultural perspective the war that took place in former Yugoslavia can be described as the war between malignant paranoid-narcissistic and depressive-narcissistic nationalisms, particularly in Bosnia and Herzegovina. Paranoid political culture underpinned by the projection mechanisms and the "enemy/escape gout" concept, represents a highly dangerous moral disorder. This culture includes negative cognition (core belief: "we are OK, but others are not; the world is a dangerous place"), negative affectedness (suspicious mind, frequent sense of danger and jeopardy, dissatisfaction, anger, rage, proneness to hatred), aggressive motivation (strike because of feeling threatened, crave for vengeance) and inappropriate behavior (exaggerated caution, persecution hidden behind the mask of savior, playing a role of defending victim, evoking conflicts). Life is perceived as a battle and the world as a battlefield; the history is made by winners; man is wolf to man; conspiracy is seen everywhere, so that conspiracy theories are in their prime; no one is to be trusted; everybody grabs whatever one can lay his/her hands on. In an environment of absolute distrust and suspicion, everyone strives to prove his/her loyalty by denunciating others before being denunciated. The cause justifies the means to it; therefore, mass crimes are not uncommon. The essence of this psychopathological political culture is the following belief: "Better get them or they'll get us first. Someone always has to loose; better make sure that we do not end up as losers. However, they commonly end up as losers.

\section{Auto- and hetero-destruction and nihilistic nationalism and religiosity}

According to Friedrich Nietzsche, nihilism means that "the highest values have become worthless" and is "just another word for emptiness and crisis people are thrown into"(see Vetlesen 2014). In its essence, a nihilistic nationalism is a an ideology and culture of death and includes negative destructive cognition (core belief: "maybe we are not OK, but they are even worse; nothing is OK anymore, but we shall change that at any cost"), negative affectedness (disappointment, anger, rage, hatred), negative motivation (extremism; "they'll get what they deserve, if necessary at the expense of our own death"; vengeance and punishment of the enemy) and inappropriate behavior (playing the role of victim that defends himself/herself in an aggressive manner, hetero- and auto-destructive behavior, terrorism). The pattern of behavior often complies with the following model: "Given the circumstances, it is better to die than to live, but we shall show them first, so that they will perish, too". One believes that he/she heroically sacrifices himself/herself for a greater good and that he/she shall be rewarded in a far more beautiful afterlife. Nihilistic nationalism almost unexceptionally goes hand in hand with terroristic activities and the recruitment of suicide (kamikaze) terrorists, the latter making use of special deliriating and brain-washing techniques.

From the above it is evident that dominating present culture characterized by double morality of preaching heaven and go on practicing hell, abundance of consumerism and greed, obsession with profit, influence and power (see Srica 2018) involves quite a lot of pathological nationalism and religious extremism.

\section{THE GLOBAL MENTAL HEALTH AND EMPATHIC CIVILISATION AS A CHALLENGE TO OUR COLLECTIVE MIND OF HUMANITY}

Taught by time, my heart has learned to glow for other's good, and melt at other's woe.

Homer

The only thing that matters is faith acting through love

The concept of collective mind has been promoted recently as a subject of intensive scientific discussions from psychological, social, ecological, economical, 
neuroscience, mathematical and computational viewpoints in order of better understanding of the behavior of living systems (Zak 2003). Human beings orient themselves to one or more aggregate groups, collectivities or communities, either real or imagined through process of identification at family, local, regional, national, international or global level. The process of transforming and joining multiple identification into a "unique and reasonably coherent whole" identity - E pluribus unum is fundamental to public and global mental health. Our world today is suffering from multiple identity disorder with multiple confronting identifications due to lacking a sense of core self of sameness, coherence, purpose and humanity. These identities each have their own way of thinking, values, interests, memories, traumas and histories and according to the EC (2012) "their diversity can be explained by the type of state, dominant religious heritage, material development and geo-political historical legacies". Healthy spirituality and religiosity and normal nationalism and transnationalism may play important roles in individual and community collective mind, resilience, quality of life, and public and global mental health promotion by directing and modeling collective thinking, collective humanistic self, compassion and social behavior, explanatory styles and world-views that promotes 'E pluribus unum' and "the brotherhood in humanity" (Jakovljevic 2017, 2018). Mental health according to the WHO (2014) "is defined as a state of well-being in which every individual realizes his or her own potential, can cope with the normal stresses of life, can work productively and fruitfully, and is able to make a contribution to her or his community". Likewise, the Public Health Agency of Canada defines mental health as "capacity of each of us and all of us to feel, think, and act in ways that enhance our ability to enjoy in life and deal with challenges we face. Psychiatric diagnosis does not exclude mental wellbeing as well as lack of diagnosis does not automatically mean mental well-being. Mental health is a positive sense of emotional and spiritual well-being that respects the importance of culture, equity, social justice, interconnections, and personal dignity" (see Brodziak et al. 2016). Specific aspects of mental health involves health and life locus of control, self-efficacy, self-actualization, sense of belonging and identity. There is growing evidence that connected communities with programs designed to promote social inclusion, networks and empathy have the potential to make an important contribution to mental well-being within the community and public mental health. Public mental health interventions aimed to promote mental wellbeing and to prevent poor mental health can be undertaken on a universal, selective or indicated basis (Faculty of Public Health \& Mental Health Foundation 2016). Creating mentally healthy people is mission of the both public and global mental health fields. The field of global mental health addresses the mental health challenges across the world such as integrating mental health screening, diagnosis, and care, providing affordable and effective community-based care, strengthening mental health training of all health personnel and laymen too, and the promoting the value of mental health as "there is no health without mental health". Mental health promotion is the complex process of enabling people to protect, improve and promote their mental health at individual and collective national and global world level. From recently public mental health activities have focused more and more on enhancing a positive, meaningful, and engaged life rather than on the control and elimination of mental disorders (Fledderus et al. 2010). Positive mental health is more than the absence of ill mental health and mental illness. It is a resource that enables people to realize their goals, satisfy their needs, and to cope with the environment in order to live a long, productive and satisfying life. Widely acknowledged environmental and social resources for mental health include: peace, home safety, economic security, compassionate society, and a stable ecosystem. Public and global mental health promotion which strengthens these resources may significantly increase individual and collective/national well-being (see CDC 2016). Countries all over the world differ substantially in their levels of well-being as well as in the religiosity of their people and types and practice of nationalism. According to the moral code of all major religions one should avoid evil deeds (rage, cruelty, anger, pride, and envy) and practice virtues (empathy, compassion, kindness, gentleness, truthfulness, selfcontrol, etc.). All these virtues may contribute to inner peace, satisfaction, well-being and ultimately to positive mental health. Psychiatry, or better to say mental health sciences, politics and religion should have the same goal, predicated on positive and optimistic view on human nature and universal ethics of brotherhood in humanity, to transform destructive and violent behaviors into constructive ones leading to positive individual, public and global mental health (Jakovljevic 2005, Boehmer 2016). According to Kangavari (2018) science, religion and politics have different functions, but not goals because their goals are: 1.to promote common good of all; 2. to promote the right to life, to employment, to education, to medical care; 3.to promote the right to living and facilities to ensure people live a healthy life in their culture.

Preventing and countering violent extremism related to malign nationalism and pathological religiosity is important strategy of the public and global mental health field (Weine \& Kansal 2019). Good news is that "the key structures that include an inclusive language, a Transformation Science, a direct democracy, reciprocal resource management, transformative learning and a collective identity and which go to make up a collective society are emerging in practice" (Brown \& Harris 2014). The making of good people, good men and women is closely associated with good public and global mental health, healthy religiosity and normal nationalism. Robert Simon (2008) "analyzed all sorts of 
bad men, from serial killers to heads of state" and shows "how spectacular failures in empathy drive the engines of evil". The good news for public and global mental health is that empathy can be taught, learned and cultivated. To empathize means to civilize and humanize, to civilize and humanize means to empathize (Krznaric 2014). Education for love, empathy and compassion are pillars and foundation of the global mental health and an esprit de corps of the empathic civilization of love (see Ferrucci 2007). Promoting dialogue among nations and religions and creating an empathic humanistic cooperative political psycho-culture may contribute to the development of global civilization of love and piece (Jakovljevic 2017, 2018). Envision a future in which nations and religions are infused with more empathy and compassion transforming our world into brotherhood in humanity. The creation of global cosmopolitan society governed by law and order is closely associated with promotion of public and global mental health. Cosmopolitanism means a better understanding of own roots and a better integration in own domicile nation as a path to empathic civilization. In search for empathic civilization and global mental health we need a critical mass of harmonious leaders in all segments of our life such as politics, science, religion, business, culture, education, sports (Srica 2018). According to Srica (2018) harmonious leaders see through the eyes of others, they are generous, love consensus and want everyone to win. We agree with Steven Pinker (2018) that "we will never have a perfect world, but there is no limit to the betterments" if we continue to apply epistemophilia with conviction that life is better than death, love is better than hate, health is better than illness, freedom is better than slavery, peace is better than war... Psychiatry, religion and politics through creative dialogue as allies could significantly contribute to the healing of our broken world as well as to promotion of compassionate society and empathic civilization.

\section{CONCLUSION}

Spirituality, religiosity, nationalism and mental health may be very closely inter-related at the individual/personal, national and global level, both in positive and negative multidirectional ways. Religiosity is a normal personality trait, religion an important component of life and culture, whereas nationalism is a normal part of personal identity and culture as well as social and political life. Malignant nationalism and morbid religiosity related to individual and collective psychopathology are huge source of hate, violence, suffering, poverty, waste of human and nature resources, all associated with a lot of public and global mental health problems and disorders. Healthy spirituality, sound religiosity and normal nationalism may contribute significantly to public and global mental health and promotion of empathic civilization through mutual understanding and creative cooperation between nations and religions.

\section{Acknowledgements: None.}

\section{Conflict of interest: None to declare.}

\section{Contribution of individual authors:}

Miro Jakovljevic: concept and design of the article, literature searches, writing manuscript, approval of the final version.

Asim Kurjak: idea, concept and design of the article, writing manuscript, approval of the final version.

Ana Jerković: comments on the concept and design of article, literature searches, writing manuscript, approval of the final version.

Azis Hasanović: concept and design of the article, writing manuscript, approval of final version.

Mijo Nikic: comments on design of the article, writing manuscript, approval of the final version.

\section{References}

1. Bhui K, Hicks MH, Lashley $M \&$ Jones $W$ : A public health approach to understanding and preventing violent radicalization. BMC Medicine 2012, 10:16 http://www.biomedcentral/1741-7015/10/16

2. Bhui K: Radicalization and mental health. Nordic Journal of Psychiatry 2018; 72:s16-s19 https://doi.org/10.1080/08039488.2018.1525640

3. Brodziak A, Rozyk-Myrta A \& Wolinska A: Does the recent intensification of nationalistic and xenophobic attitudes in Eastern European countries adversely affect public mental health? BMC Public Health 2016;16:1115 DOI 10.1186/s12889-016-3785-3

4. Brown VA \& Harris JA: Living with transformational change - A future of the collective mind. In Brown VA \& Harris JAL: A Human Capacity for Transformational Change - Harnessing the collective mind, 18-47. Routledge, London and New York 2014

5. CDC (Centers for Disease Control and Prevention): Health-related Quality of Life - Well-being Concepts, 2016. https://www.cdc.gov

6. Cole NL: The concept of collective consciousness. Thought Co, Jun. 5, 2019, thoughtco.com/collective-consciuosnessdefinition-3026118

7. Combs A \& Krippner S: Collective consciousness and the social brain. Journal of Consciousness Studies 2008; 15:264-276 https://www.researchgate.net

8. Corsini R. The Dictionary of Psychology-Brunner/Mazel, Taylor\& Francis Group, 2002

9. De Marinis $V \&$ Boyd-MacMillan E: A mental health approach to understanding violent extremism. RAN Centre for Excellence: Ex Post Paper, RAN Policy \& Practice, 3 June 2019, Paris (Fr)

10. Encharta Concise English Dictionary, Student Edition, Bloomsbury Publishing Inc, London 2001

11. EC (European commission): The Development of European Identity/Identities: Unfinished Business - A Policy Review, Directorate-General for Research and Innovation, Socioeconomic Sciences and Humanities, Brussels, 2012

12. Faculty of Public Health \& Mental Health Foundation: Better Mental Health for All: A Public Health Approach to Mental Health Improvement, London 2016 
13. Ferrer JN: Revisioning Transpersonal Theory - A Participatory Vision of Human Spirituality. State University of New York Press, Albany 2002

14. Ferrucci P: The Power of Kindness - The Unexpected Benefits of Leading s Compassionate Life. Penguin Books, London, 2007

15. Gerhardt S: The Selfish Society - How We All Forgot toLove One Another and Made More Money Instead. Simon \& Schuster, London, 2010

16. Gilbert P: The Compassionate Mind - A New Approach to Life Challenges. Constanble, London 2013

17. Gotzsche-Astrup $O$ \& Lindekilde L: Either or? Reconciling on mental health and extremism using dimensional ratherthancategorical paradigm. J Forensic Sci 2019; 64:982-988

18. Griffith JL: Religion that Heals, Religion that harms - A Guide for Clinical Practice. The Guilford Press, New York \& London, 2010

19. Harrari YN: Sapiens - A Brief History of Humankind. Vintage Books, London 2011

20. Harrari YN: Homo Deus - A Brief History of Tomorrow. Vintage, London 2017

21. Harrari YN: 21 Lessons for the 21st Century. Jonathan Cape, London, 2018

22. Hocking VT, Brown VA \& Harris JA: Tackling wicked problems through collective design. Inteligent Buildings International 2016; 8:24-36 http://dx.doi.org/10.80/17508975.2015.1058743

23. Jakovljevic M \& Tomic Z: Global and public mental health promotion for empathic civilisation: The role of political psychocultures. Psychiatr Danub 2016; 28:323-333

24. Jakovljevic M: Religion and spirituality from perspective of public and global mental health promotion. Psychiatr Danub 2017a; 29:236-237

25. Jakovljevic M: Resilience, psychiatry and religion from public and global mental health perspective - From divide to dialogue and cooperation in the search of humanistic self, compassionate society and empathic civilization. Psychiatria Danubina 2017b; 29:238-244. https://doi.org/10.24869/psyd.2018.380

26. Jakovljevic M: Empathy, sense of coherence and resilience: Bridging personal, public and global mental health and conceptual synthesis. Psychiatr Danub 2018; 4:380-384 https ://doi.org/10.24869/psyd.2017.237

27. Juergensmeyer M: Religious nationalism in a global world. Religions 2019; 10, 97; doi:10.3390/rel10020097
28. Kangavari $R G$ : The complex relationship among troika of religion, science, and politics: From an Islamic perspective. In Kurjak A, Chervenak FA, McCullough LB \& Hasanovic A (eds): Science and Religion, Synergy not Scepticism, 239-260. Jaypee Brothers Medical Publisher, New Delhi, London \& Panama, 2018

29. Krznaric R: Empathy: A Handbook for Revolution, Penguin Random House, 2014

30. Levin J: How faith heals: A theoretical model. EXPLORE 2009; 5:77-96

31. Pargament KI: The Psychology of Religion and Coping Theory, Research and Practice. The Guilford Press, New York \& London, 1997

32. Pinker S: Enlighment Now - Case for Reason, Science, Humanism and Progress. Allen Lane, an imprint of Penguin Books, UK, 2018

33. Simon RI: Bad Men Do What Good Men Dream - A Forensic Psychiatrist illuminates the Darker Side of Human Behavior, American Psychiatric Publishing, Inc., Washington DC \& London 2008

34. Skrbis Z: Nationalism in a transnational context: Croatian diaspora, intimacy and national imagination. Revija za sociologiju 2001; 32:133-145

35. Slade M: Personal Recovery and Mental Illness - A Guide for Mental Health Professionals. Cambridge University Press, 2011

36. Srica V: The world is broken, harmony-based leadership may fix it. In Kurjak A, Chervenak FA, McCullough LB \& Hasanovic A (eds): Science and Religion, Synergy not Scepticism, 261-278. Jaypee Brothers Medical Publisher, New Delhi, London \& Panama, 2018

37. Wahlbeck K: Public mental health: the time is ripe for translation of evidence into practice. World Psychiatry $2015 ; 14: 36-42$

38. Waltner-Toes D: Foreword - Transcending diversity: harnessing the collective mind. In Brown VA \& Harris JA: A Human Capacity for Transformational Change Harnessing the collective mind, ix-xiv. Routledge, London and New York, 2014

39. Weine $S$ \& Kansal $S$ : What should global mental health do about violent extremism? Global Mental Health 2019; 6.e14, page 1-7. doi:10.1017/gmh.2019.12

40. Wikipedia: Religious nationalism. en.m.wikipedia.org/wik 41. Wikipedia: Ultranationalism. en.m.wikipedia.org/wik

42. Zak M: From collective mind to communication. Complex Systems 2003; 14:335-361

Correspondence:

Professor Miro Jakovljevic, MD, PhD

Department of Psychiatry and Psychological Medicine,

University Hospital Centre Zagreb

Kišpatićeva 12, 10000 Zagreb, Croatia

E-mail: psychiatry@kbc-zagreb.hr 